
\title{
R Reserach S Suare \\ Influence Of Marketing Mix On Adolescents' Voluntary HIV Testing Uptake In Tanzania: Experience From Physical Evidence
}

Stephen Furaha Matemba ( $\sim$ smatemba@yahoo.com)

Ministry of Health Community Development Gender Elderly and Children https://orcid.org/0000-00023374-8635

Elia John

The University of Dodoma

Ismail J Ismail

The University of Dodoma

Tumbwene Mwansisya

University of Aghakan

Research article

Keywords: VCT uptake, marketing mix, physical evidence, adolescents, Tanzania

Posted Date: May 29th, 2020

DOl: https://doi.org/10.21203/rs.3.rs-30142/v1

License: (c) (i) This work is licensed under a Creative Commons Attribution 4.0 International License. Read Full License 


\section{Abstract}

Background In public health, traditional 4Ps (product, price, place and promotion) of the marketing mix have been successfully used to influence clients/patients to adopt desired health behaviors and health status changes in reproductive health, tuberculosis (TB), malaria, child survival and human immuno-virus (HIV) interventions. However, the use of additional 3Ps (Physical evidence, People and Process) of the marketing mix have rarely been used in public health interventions. This study examined the influence of physical evidence on voluntary counseling and testing (VCT) uptake among adolescents in Tanzania.

Methods A cross-sectional study design using quantitative method was conducted in Dodoma. A multistage random sampling method was used to select nine secondary schools and 449 study participants. Self-administered structured questionnaire was used. Data was analyzed using SPSS v17. Relationship between independent and dependent variables was analyzed using binary logistic regression and correlation analysis with $p$-value of $\otimes 0.5$ regarded as significant. Binary logistic regression was used to determine predictors of VCT uptake. Descriptive statistics was used to analyze participants' characteristics and ranking of physical evidence variables' on VCT uptake among adolescents.

Results Of 449 study participants, $54 \%$ and $46 \%$ were females and males respectively. The participants' age range was $12-19$ years. $96 \%$ of respondents had knowledge of VCT, $90.6 \%$ were willing to test for HIV, however; $78 \%$ had not tested for HIV. Physical evidence variable modern equipment was highly ranked influential variable regarding VCT uptake. Independent variables modern equipment, physical facility, personnel and materials were found predictors of VCT uptake. Participant characteristics age and school type were also predictors for VCT uptake.

Conclusions Despite majority of adolescents had knowledge on VCT service and were willing to test for HIV, VCT uptake was low. Meaning that knowledge and willingness a lone are not enough to influence VCT uptake. Physical evidence variables modern equipment, physical facility, personnel and materials when integrated in HIVprevention strategies and interventions can increase VCT uptake among adolescents in Tanzania. Consideration of individual expectation variations and other predictor variables like age and school type need to be incorporated in designing VCT interventions.

\section{Background}

Since the onset of HIV / AIDs in the world (1990-2016), 71 million people have been infected with HIV. Of which, adolescents (10-19 years) and young(1) people (15-24 years) represent key population that is highly affected by HIV(2). In Tanzania, HIV remains to be one of the main national health priorities, since in 2016, about 1.4 million people lived with HIV(1). The HIV infection causes a negative impact to effected communities through loss of the most productive segment of the society leading into economic decline to affected countries(3,4).Efforts have been done globally and at national levels to combat HIV / AIDs pandemic, including establishment of 90-90-90 targets to AIDS epidemic by 2020, which emphasizes on $90 \%$ of people living with HIV (PLHIV) to know their HIV status by year 2020(5). This led 
to strengthening of VCT strategies globally, since VCT is regarded as one of the important components of HIV prevention, treatment, care and support(6). It is potentially effective and affordable method of preventing HIV infection in developing countries.

Despite all these efforts, VCT uptake has been low. Example,by the end of 2014 there were still 17 million people out of 37 million people who were living with HIV who had not tested for HIV(5). In Tanzania alone, testing rates in 2012 was $35.4 \%(7)$, while in 2014 was $28.4 \%$ (8). Among adolescents, $65.8 \%$ male and $43 \%$ female of $15-24$ years had never tested for $\mathrm{HIV}(7)$. The reason for low uptake of VCT remains unclear.

In Public health, health promotion strategy has been the main approach used in implementation of public health interventions(9). Whereas in business, marketers have been working towards changing perceptions of their customers towards their services and products through working on the marketing mix elements, the 4Ps (product, price, place and promotion)(10). Because of the inherent intangibility and nature of the service, the additional three Ps i.e physical evidence, process and people were introduced(11). The new components are important in service promotion in the eyes of the customers. It is agreed that there is variation in customer perception between individuals, which has great impact on buying decisions(12). Marketers work on controlling elements of the marketing mix i.e product, price, place, promotion, people, process, physical evidence to change customer perception in order to influence buying decisions(11).

Through the concept of social marketing, marketing concepts have been adopted in public health interventions to influence desired behavioral change(13), giving positive results. Example, in a study conducted in Cameroon to assess the impact of condom use among youth aged 15-24, when market mix elements, the 4Ps i.e product, price, promotion and place were integrated in the intervention condom use among adolescents increased(14). Therefore, there is the need to assess the influence of the additional 3Ps i.e people, process and physical evidence on public health interventions. Therefore, this study aimed at determining the influence of physical evidence on VCT uptake among adolescents in Tanzania. Adolescent are among the most risk groups for contracting HIV infection and highly underrepresented among VCT clients(15).

\section{Methods}

\section{Research design}

The study used cross-sectional study design together with quantitative method to determine the physical evidence of VCT uptake.

\section{Study area}

The study was conducted in Dodoma city, which is part of the seven districts in Dodoma Region. The city has four divisions, 41 wards and 51 secondary schools of which 36 are public secondary schools and 15 private secondary schools with a total of 23,231 in all secondary schools(16). The reason of choosing 
Dodoma region was because it has recently become a city, which has resulted to an influx of people from different parts of the country. This may contribute to increasing risk of HIV infection.

\section{Study population}

The target population was secondary school students in Dodoma city who were enrolled in Government schools. Participants were given the chance to decide on whether to be in the study or not. For those participants who decided not to participate they were discontinued at the earliest stage of recruitment.

\section{Sample size}

The sample size of 391 was obtained by using Yamane sample calculation formulae. Where population size " $N$ " was 19,200; margin of error 0.05 , confidence interval $95 \%$. However, a convenient sample size of 500 was used.

\section{Sampling method}

A multi-stage systematic random sampling procedure was used to identify government secondary schools and study participants.

Stage 1 was for identification of secondary schools. A list of 36 public secondary schools arranged in ascending order of their names was created. Based on number of schools required, which was nine, 36 schools were divided by nine to get $\mathrm{n}^{\text {th }}$ value equal to four. Then the first school was randomly selected by lottery method, followed by selection of every fourth school starting from thefirst selected school.

Stage 2 was identification of classes through stratification method. For every secondary school stratification was based on number of classes, since other schools had form I-IV, while others form I-VI.

Stage 3 stratified the classes further based on gender for purpose of equal presentation among females and males. Eventually, the study participants were selected through systematic random selection within each stratum. Within each stratum, sampling interval was calculated based on the required sample size for each stratum. Population size within the stratum was divided by required sample size to get the sample interval. The list of students in ascending order based on their names was created for each stratum. Starting participant was selected randomly by lottery method. Using the calculated sampling interval, every " $\mathrm{n}$ "h" student from the first student was selected to participate in the study.

\section{Data collection}

A self-administered structured questionnaire in both English and Kiswahili was developed. The questionnaire comprised of four sections. Section I related to background information, Section II on knowledge of HIV/VCT services, Section III on uptake of VCT services and Section IV on service quality dimension and service marketing mix. Questions on physical evidence adopted and modified from standardized Servqual questionnaire, considering service quality dimension and service marketing model. 
In this model, service quality model is classified according to the three service marketing elements physical evidence, people and process(17).

\section{Validity and Reliability}

To ensure validity and reliability of the research tools, pretesting of the Swahili questionnaire was done using a convenient sample of 26 (13 females and 13 males). Needful phrasing adjustments particularly on physical evidence variable questions were done.

\section{Study variables}

The study had one dependent variable, VCT uptake and four independent variables. The independent variables include modern equipment, physical facility, personnel and material. Influence of independent variables on VCT uptake was determined by asking participants the level of influence an independent variable has on VCT uptake using a five-point Likert Scale questions.

\section{Data management and analysis}

Data collected was coded into computer, cleaned, validated and eventually analyzed using statistical package for social sciences (SPSS) version 17. Descriptive statistics was used to analyze participants' characteristics, VCT uptake among participants and ranking of physical evidence variables. Binary logistic regression analyzed the association between independent and dependent variables, using odds ratio and P-value $\otimes 0.5$. Correlation analysis analyzed association between independent and dependent variables with level of significance $P$ value $\otimes 0.5$.

\section{Ethical consideration}

Before the study took place, it was reviewed by the Ethical Review Committee of the University of Dodoma. Study participants consent was considered before engaged in the study. Participants were introduced about the study, they were given time to ask questions in a frank and friendly way. Upon participant's discretion, he/she was given opportunity to decide on whether to participate or not in the study. Participants' information was secured.

\section{Results}

\section{Response rate}

Out of 500 study participants, only 449 participants participated in the study giving a response rate of $89.8 \%$

\section{Participants' characteristics}

Table 1 shows that among 449 participants, $54 \%$ were females and $46 \%$ male. The age distribution of participants ranged from 12 to 19 years, with majority of participants being 16-18 years (61\%). Almost 
half of participants were from Form III and IV, with majority being Christians (73\%) and day scholars (76\%). Most of the participants had heard about the VCT service (93\%) and had proper knowledge about the VCT service (96\%).

Table 1: Participant's characteristic distribution $(n=449)$

\begin{tabular}{lll} 
Variable & Value & No. (\%) \\
\hline Sex & Male & $205(45.7 \%)$ \\
\hline & Female & $244(54.3 \%)$ \\
\hline Age (years) & & \\
\hline & Mean ( \pm SD) & $148( \pm 1.58)$ \\
\hline & 12 to 15 & $130(29 \%)$ \\
\hline Education & 16 to 18 & $272(60.6 \%)$ \\
\hline & 19 to 24 & $47(10.5 \%)$ \\
\hline & Form I \& II & $167(37.2 \%)$ \\
\hline Form III \& IV & $217(48.3 \%)$ \\
\hline Type of school & Form V \& VI & $65(14.5 \%)$ \\
\hline & Day & $340(75.7 \%)$ \\
\hline Knowledge of VCT & Yes & $429(96 \%)$ \\
\hline Neard of VCT & Boarding & $20(4 \%)$ \\
\hline & Yes & $416(93 \%)$ \\
\hline & No & $33(7 \%)$ \\
\hline
\end{tabular}


Given the appropriate sample size of 449 , majority of the adolescents had not tested for HIV (350, 78\%) despite the fact that most of them had knowledge $(429,95 \%)$ and were willing to test for HIV (406, 90.6\%). This is demonstrated in Table 2.

Table 2: Responders' HIV testing status and willingness to test for HIV ( $n=449)$

\begin{tabular}{llll} 
& & No. & $\%$ \\
\hline Testing status for HIV & Yes & 99 & 22 \\
\cline { 2 - 4 } & No & 350 & 78 \\
\hline Willingness to Test for HIV & Yes & 406 & 90.6 \\
\cline { 2 - 4 } & No & 42 & 9.4
\end{tabular}

Descriptive statistics on relationship between the service marketing mix element, physical evidence and VCT uptake

Table 3 shows that physical evidence variables, modern looking equipment and appealing physical facilities were highly ranked priorities that could influence adolescents' VCT uptake.

Table 6. 3: Descriptive statistics of variables under Physical Evidence (Service quality dimension Tangible) $(\mathrm{n}=449)$

S/N Statements

$1 \quad$ Excellent Hospitals will have modern looking equipment

2 The physical facilities at excellent hospitals will be visually appealing

3 Personnel at excellent hospitals/ clinics will be neat in appearance

$4 \quad$ Materials associated with the service (such as pamphlets or statements) will be visually appealing in an excellent hospital/clinic

Average Physical evidence/ tangible SERVQUAL scores
Mean STD Rank

Deviation

68

1.84

1

$5.33 \quad 1.89$

2

4.12

2.11

4

5

1.95

3

5

1.37 
Results in Table 4 show that physical evidences included in the model contribute to $65 \%$ (Cox \& Snell R Square) and 70\% (Nagelkerke R Square) in explaining VCT uptake among adolescents with -2 Log likelihood of 442.987.

Table 4: Model summary of the fitted physical evidence

\begin{tabular}{llll} 
Step & -2 Log likelihood & Cox \& Snell R Square & Nagelkerke R Square \\
\hline 1 & $442.987^{\mathrm{a}}$ & .650 & .700
\end{tabular}

\section{Modern equipment and VCT uptake among adolescents}

This variable was found to have different results across all categories included. The results showed that, compared to those who responded with strongly disagree, those with disagree have beta of -0.887 , odd ratio of 0.428 and $p$ value of 0.141 , those with neutral responses have beta of -0.747 , odd ratio of 0.110 and $p$ value of 0.385 while two categories, 'agree' and 'strongly agree' have significant influence with $p$ value of 0.014 and 0.01 respectively. This means generally, compared to those who disagree with the fact that modern equipment is a determinant, those with agree responses are very significant and hence contribute to the VCT uptake among adolescents. It further means that, any attempt to improve modern equipment among those who agree and strongly agree will increase the VCT uptake among adolescents. On the other hand, the findings show that, the chances of up taking VCT is $5 \%(1.055)$ and $98 \%(1.982)$ among those who agree and strongly agree respectively. These findings are demonstrated in Table 5.

\section{Correlation analysis between modern equipment and VCT uptake among adolescents}

Pearson correlation analysis between modern equipment and VCT uptake among adolescents shows a positive correlation of 0.518 and significant value of 0.007 indicating that, increases in modern equipment means increasing VCT uptake among adolescents as shown in Table 6.

\section{Physical facility and VCT uptake among adolescents}

Physical facility was found to have significant relationship with 'agree' and 'strongly agree' categories with beta and $p$ values of $1.295,0.022$ and $1.115,0.007$ respectively. This means that, those who agreed with physical facility had high odds of 1.745 (75\%) and 1.891 (89\%) of up- taking VCT than those who responded with disagree, which is shown in Table 5.

\section{Correlation analysis between physical facilityand VCT uptake among adolescents}


Pearson correlation analysis between physical facilities and VCT uptake among adolescents shows a positive correlation of 0.666 with $p$ value of 0.016 indicating that, increases in physical facilities means increasing VCT uptake among adolescents.

\section{Personnel and VCT uptake among adolescents}

Personnel of the staff was another variable which was found to have likelihood of 1.531 (53\%) and 1.523 (52\%) for agree and strongly agree responses respectively on up-taking VCT than those who responded with disagree. This means that, the variable is determinant as it is significant with 0.011 and $0.029 p$ values respectively. On the other hand, the variable was found to have positive correlations for neutral, agree and strongly agree responses as shown in Table 5.

\section{Correlation analysis between personnel and VCT uptake among adolescents}

Pearson correlation analysis between personnel and VCT uptake among adolescents shows a positive correlation of 0.424 with $p$ value of 0.012 indicating that, improvement in personnel will improve VCT uptake among adolescents. The details are shown in Table 6.

\section{Material and VCT uptake among adolescents}

As shown in Table 5, materials evidence was analyzed to have a direct and significant correlation with VCT up - taking. The results show that, the likelihood of up taking VCT with respect to material is 225 with $p$ value of 0.002 for strongly agree response and likelihood of 217 with $p$ value of 0.016 for agree response. This means that, improving material will positively increase up taking of VCT by 1.829 and 2.923 for strongly agree and agree responses respectively compared tothose who responded as disagree.

\section{Correlation analysis between material and VCT uptake among adolescents}

The results in Pearson correlation analysis between material and VCT uptake among adolescents shows a positive correlation of 0.381 with $p$ value of 0.036 indicating that, improvement of materials in the hospital will significantly improve VCT uptake among adolescents.

Results of the findings revealed that, generally, physical evidencecontributes significantly to the VCT uptake among adolescents as shown in Table 6.

Table 5: Binary logistic regression results of the physical evidences of VCT uptake among adolescents 


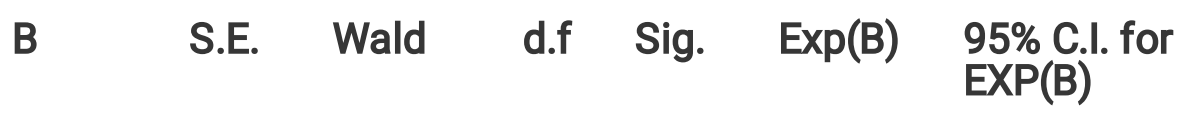

Lower Upper

\begin{tabular}{|c|c|c|c|c|c|c|c|c|c|}
\hline \multirow[t]{5}{*}{$\begin{array}{l}\text { Step } \\
1^{\text {a }}\end{array}$} & $\begin{array}{l}\text { Modern Equip } \\
\text { (Strongly dis) }\end{array}$ & & & 3.301 & 4 & .770 & & & \\
\hline & $\begin{array}{l}\text { Modern Equip } \\
\text { (Disagree) }\end{array}$ & -.887 & .602 & 2.171 & 1 & .141 & .428 & .746 & 7.904 \\
\hline & $\begin{array}{l}\text { Modern Equip } \\
\text { (Neutral) }\end{array}$ & -.747 & .860 & .755 & 1 & .385 & .110 & .391 & 11.379 \\
\hline & $\begin{array}{l}\text { Modern Equip } \\
\text { (Agree) }\end{array}$ & .053 & .495 & .012 & 1 & .014 & 1.055 & .400 & 2.783 \\
\hline & $\begin{array}{l}\text { Modern Equip } \\
\text { (Strongly ag) }\end{array}$ & .019 & .489 & .001 & 1 & .010 & 1.982 & .376 & 2.561 \\
\hline
\end{tabular}

\begin{tabular}{lllllllllll}
$\begin{array}{l}\text { Phys facility } \\
\text { (Strongly dis) }\end{array}$ & & & 7.480 & 4 & .279 & & & \\
\hline $\begin{array}{l}\text { Phys facility } \\
\text { (Disagree) }\end{array}$ & -1.135 & .495 & 5.264 & 1 & .106 & .322 & .122 & .848 \\
$\begin{array}{l}\text { Phys facility } \\
\text { (Neutral) }\end{array}$ & -1.140 & .706 & 2.608 & 1 & .550 & .320 & .080 & 1.276 \\
\hline $\begin{array}{l}\text { Phys facility (Agree) } \\
\text { Phys facility }\end{array}$ & 1.295 & .493 & .357 & 1 & .022 & 1.745 & .283 & 1.957 \\
\hline $\begin{array}{l}\text { (Strongly ag) } \\
\text { (1.115 }\end{array}$ & .430 & .072 & 1 & .007 & 1.891 & .384 & 2.069 \\
\hline
\end{tabular}

\begin{tabular}{llllllllll}
$\begin{array}{l}\text { Personnel (Strongly } \\
\text { dis) }\end{array}$ & & & 7.447 & 4 & .281 & & & \\
\hline $\begin{array}{l}\text { Personnel } \\
\text { (Disagree) }\end{array}$ & -.164 & .410 & .160 & 1 & .009 & .849 & .380 & 1.896 \\
\hline Personnel (Neutral) & .233 & .507 & .212 & 1 & .045 & 1.792 & .293 & 2.139 \\
\hline Personnel (Agree) & .632 & .451 & 1.963 & 1 & .011 & 1.531 & .219 & 1.287 \\
\hline $\begin{array}{l}\text { Personnel (Strongly } \\
\text { ag) }\end{array}$ & .647 & .426 & 2.306 & 1 & .029 & 1.523 & .227 & 1.207 \\
\hline
\end{tabular}


B S.E. Wald d.f Sig. $\operatorname{Exp(B)~} 95 \%$ C.I. for $\operatorname{EXP}(B)$

Lower Upper

Materials (Strongly dis)

$\begin{array}{lll}13.112 & 4 & .227\end{array}$

$\begin{array}{lllllllll}\text { Materials (Disagree) } & 1.632 & .524 & 1.457 & 1 & .027 & 1.881 & .674 & 5.250\end{array}$

$\begin{array}{lllllllll}\text { Materials (Neutral) } & 1.832 & .557 & 2.229 & 1 & .035 & 2.297 & .771 & 6.843\end{array}$

$\begin{array}{lllllllll}\text { Materials (Agree) } & 2.923 & .521 & 3.140 & 1 & .016 & 2.517 & .907 & 6.988\end{array}$

$\begin{array}{lllllllll}\text { Materials (Strongly } & 1.829 & .583 & 9.835 & 1 & .002 & 225 & 1.985 & 19.518\end{array}$
ag)

.000

Table 6: Correlation analysis between modern equipment, physical facility, personnel,material and VCT uptake among adolescents 


\begin{tabular}{|c|c|c|c|}
\hline & & Test for HIV & Variable \\
\hline \multirow[t]{3}{*}{ Test for HIV } & Pearson Correlation & 1 & $.518^{*}$ \\
\hline & Sig. (2-tailed) & & .007 \\
\hline & $\mathrm{N}$ & 449 & 449 \\
\hline \multirow[t]{3}{*}{ Modern equipment } & Pearson Correlation & $.518^{*}$ & 1 \\
\hline & Sig. (2-tailed) & .007 & \\
\hline & $\mathrm{N}$ & 449 & 449 \\
\hline \multirow[t]{3}{*}{ Test for HIV } & Pearson Correlation & 1 & $.666^{*}$ \\
\hline & Sig. (2-tailed) & & .016 \\
\hline & $\mathrm{N}$ & 449 & 449 \\
\hline \multirow[t]{3}{*}{ Physical facilities } & Pearson Correlation & $.666^{*}$ & 1 \\
\hline & Sig. (2-tailed) & .016 & \\
\hline & $\mathrm{N}$ & 449 & 449 \\
\hline \multirow[t]{3}{*}{ Test for HIV } & Pearson Correlation & 1 & $.424^{*}$ \\
\hline & Sig. (2-tailed) & & .012 \\
\hline & $\mathrm{N}$ & 449 & 449 \\
\hline \multirow[t]{3}{*}{ Personnel } & Pearson Correlation & $.424^{*}$ & 1 \\
\hline & Sig. (2-tailed) & .012 & \\
\hline & $\mathrm{N}$ & 449 & 449 \\
\hline \multirow[t]{3}{*}{ Test for HIV } & Pearson Correlation & 1 & $.381^{*}$ \\
\hline & Sig. (2-tailed) & & .036 \\
\hline & $\mathrm{N}$ & 449 & 449 \\
\hline \multirow[t]{3}{*}{ Materials } & Pearson Correlation & $.381^{*}$ & 1 \\
\hline & Sig. (2-tailed) & .036 & \\
\hline & $\mathrm{N}$ & 449 & 449 \\
\hline
\end{tabular}




\section{Discussion}

Despite the fact that most of adolescents had knowledge of HIV (95\%)and were willing to test for HIV (90\%), very few had tested for HIV (22\%).Similar findings were observed in a study conducted in Arusha Tanzania(18). However, an Ethiopian study showed higher VCT uptake among adolescents(19). This could be due to differing socio-cultural characteristics and beliefs between countries. There is an indication that knowledge and willingness alone are not enough to influence adolescents to uptake VCT.

Among the seven respondent characteristics (sex, age, education, religion, type of school, awareness and knowledge of VCT), only two characteristics which are age and school type are predictors for VCT uptake among adolescents. This is contrary to a study in Arusha that showed sex, age, education level and religion as predictors(18). The difference could be attributed to differing contextual environment that may influence their behaviors. For age, adolescents 18 years and above had higher chances of VCT uptake, which is similar to a study conducted by Sanga et. al.,(18).

Variation on adolescents' expectations on physical evidence variables concerning to VCT uptake was observed, with higher expectationson modern equipments and physical facility that are attractive or appealing. This indicates that individuals have different service expectations, which when met may lead to client satisfaction and increase service utilization or uptake $(20,21)$. Understanding of clients' expectations and needs is important step towards delivering of high quality service(22,23)that meets clients' satisfaction.

Physical evidence was observed to have a significant influence on VCT uptake. Presence of modern looking equipments in healthcare facilities have shown to have significant influence on VCT uptake among adolescents. Similar findings were observed in other studies(24).

Presence of physical facilities which are visually appealing have shown to have significant influence on VCT uptake among adolescents. Angoodet. Al., went further to comment on importance of a welldesigned physical healthcare facility that is attractive to patients/clients(25).

Chaipoopirutanaet. Al., showed that signs, artifacts, amenities and symbol are other important components of physical evidence (26).

Neat appearance of personnel significantly influences VCT uptake among adolescents. Jager and Plooy also had similar findings that support personnel neatness in healthcare facilities (24).

Presence of visual appealing materials related with service (such as statements orpamphlets) and equipments have shown significant influence on VCT uptake. This was supported by Jagerand Plooy study (24).

\section{Study Limitation}


The study used questionnaire to collect data, which predisposed the study participants to information bias. Participants could likely interpret differently the questions, thus providing wrong responses. Moreover, the study was limited to adolescents who are attending secondary school, therefore the information may not reflect the opinions of out of school adolescents.

\section{Conclusion}

Despite majority of adolescents had knowledge on VCT service and were willing to test for HIV, VCT uptake was low. Meaning that knowledge and willingness a lone are not enough to influence VCT uptake. Moreover, age and school type are predictors of adolescents' VCT uptake. Examination on influence of physical evidence of the service marketing mix elements on VCT uptake among adolescents revealed that physical evidence has significant influence on adolescents' VCT uptake.

Therefore, there is a need for Public Health managers and policy makers to integrate the physical evidence in public health interventions in order to increase VCT uptake among adolescents in Tanzania. Emphasis should be put to ensure that healthcare facilities have modern looking equipments, physical facilities that are visually attractive, healthcare workers who are neat and appealing, and service materials that are visually attractive in order to attract adolescents to uptake VCT.

\section{Abbreviations}

HIV Human Immuno-virus

AIDS $\quad$ Acquired Immune Disease

4Ps $\quad$ Product, Price, Place and Promotion

3Ps Physical evidence, People and Process

VCT Voluntary Counselling and Testing

TB Tuberculosis

PLHIV People Living with HIV

Servqual Service quality

\section{Declarations}

\section{Ethics approval and consent to participate}

Ethical Review Committee of the University of Dodoma approved the study. Study participant consent was considered before engaging to the study. Written informed consent was obtained from a parent or guardian for participants under 16 years old. 


\section{Consent of publication}

Not Applicable

\section{Availability o data and materials}

The datasets generated and / or analysed during the current study are available from the corresponding author on reasonable request.

\section{Competing interests}

The authors declare that they have no competing interests.

\section{Funding}

Not applicable

\section{Authors' contributions}

SFM, played main role in developing the idea, designing the study, collecting and analysing the results, and preparing and submitting the manuscript. IJ, participated in data analysis and general supervision. EJ, participated in developing the idea, designing the study, general supervision. TM, participated in preparation and submission of the manuscript. All authors have read and approved the manuscript.

\section{Acknowledgement}

We kindly acknowledge Dodoma City Council Authority for providing permission to conduct the study. We as well thank secondary schools' head teachers and participating students for enabling the study to be conducted successfully. Special appreciations should go to Rehema Mahembe, research assistant for participating in data collection and data entry.

\section{Author information}

SM; Doctor of Dental Surgery, Masters in Public Health, Licentiate degree Medicine, Masters in Business Administration

Current position; member of the Health Sector Resource Secretariat Ministry of Health, Community Development, Gender, Elderly and Children

\section{References}

1. Girum T, Wasie A, Worku A. Trend of HIV/AIDS for the last 26 years and predicting achievement of the $90-90-90$ HIV prevention targets by 2020 in Ethiopia: a time series analysis. BMC Infect Dis 
[Internet]. 2018/07/13. 2018;18(1):320. Available from:

http://www.ncbi.nlm.nih.gov/pubmed/29996776

2. UNICEF. Adolescent deaths from AIDS tripled since 2000 - UNICEF | Press centre | UNICEF. 2015; undefined-undefined.

3. Simtowe F, Kinkingninhoun-Medagbe FM. The impact of HIV/AIDS on labor markets, productivity and welfare in Southern Africa: A critical review and analysis. Vol. 6, African Journal of Agricultural Research. 2011. p. 2118-31.

4. Azomahou TT, Boucekkine R, Diene B. HIV/AIDS and development: A reappraisal of the productivity and factor accumulation effects. In: American Economic Review. American Economic Association; 2016. p. 472-7.

5. WHO. WHO | Global health sector strategy on HIV, 2016-2021 [Internet]. World Health Organization; 2016 [cited 2020 Feb 2]. Available from: https://www.who.int/hiv/strategy2016-2021/ghss-hiv/en/

6. WHO. HIV and adolescents: guidance for HIV testing and counselling and care for adolescents living with HIV: recommendations for a public health approach and considerations for policy-Makers and managers. Geneva; 2013. 81 p.

7. TACAIDS. Tanzania HIV/AIDS and Malaria Indicator Survey 2011-2012. Dar-es-Salaam; 2012.

8. Health TM of. The United Republic Of Tanzania Global Aids Response Country Progress Report. 2014.

9. WHO. The Ottawa charter for health promotion. In: World Health Organization Regional Publications European Series. 1992. p. 3-7.

10. Išoraitė M. Marketing mix theoretical aspects. Int J Res [Internet]. 2016 [cited 2020 Feb 2];4(6):25-37. Available from: http://granthaalayah.com/Articles/Vol4Iss6/04_IJRG16_C06_07.pdf

11. Khan MT. The concept of "marketing mix" and its elements. A conceptual review paper. Int J Inf Manag. 2014;6(2):95-107.

12. Constantinides E. Influencing the online consumer's behavior: The Web experience. Vol. 14, Internet Research. 2004. p. 111-26.

13. Firestone R, Rowe CJ, Modi SN, Sievers D. The effectiveness of social marketing in global health: A systematic review. Vol. 32, Health Policy and Planning. Oxford University Press; 2017. p. 110-24.

14. Meekers D, Agha S, Klein M. The impact on condom use of the " $100 \%$ Jeune" social marketing program in Cameroon. J Adolesc Heal. 2005 Jun;36(6).

15. McCauley AP. Equitable access to HIV counseling and testing for youth in developing countries: a review of current practice. 2004;

16. City D. Dodoma City Council. Secondary Education. [Internet]. 2018. Available from: ttp://www.dodomamc.go.tz/storage/app/media/uploadedfiles/DODOMA MUNICIPAL PROFILE.pdf.)

17. Yarimoglu EK. A Review on Dimensions of Service Quality Models. J Mark Manag. 2014th ed. 2014;2(2):79-93. 
18. Sanga Z, Kapanda G, Msuya S, Mwangi R. Factors influencing the uptake of Voluntary HIV Counseling and Testing among secondary school students in Arusha City, Tanzania: a cross sectional study. BMC Public Health [Internet]. 2015/05/03. 2015;15:452. Available from: http://www.ncbi.nlm.nih.gov/pubmed/25933806

19. Addis Z, Yalew A, Shiferaw Y, Alemu A, Birhan W, Mathewose B, et al. Knowledge, attitude and practice towards voluntary counseling and testing among university students in North West Ethiopia: a cross sectional study. BMC Public Health [Internet]. 2013/08/07. 2013;13:714. Available from: http://www.ncbi.nlm.nih.gov/pubmed/23914738

20. Papanikolaou V, Zygiaris S. Service quality perceptions in primary health care centres in Greece. Heal Expect. 2014;17(2):197-207.

21. Ng JHY, Luk BHK. Patient satisfaction: Concept analysis in the healthcare context. Patient Educ Couns. 2019 Apr 1;102(4):790-6.

22. Valarie A Zeithaml A Parasuraman LLB. The Nature and Determinants of Customer Expectations of Service. J Acad Mark Sci. 1993;21:1-12.

23. Valarie A. Zeithaml A. Parasuraman LLB. The Behavioral Consequences of Service Quality. J Mark. 1996;60:31-46.

24. Jager J De, Plooy T. Tangible Service-Related Needs of Patients in Public Hospitals in South Africa. 2nd Int Res Symp Serv Manag Yogyakarta, Indones. 2011;

25. Dharmesh Motwani VS. Service marketing mix of indian hospitals: a critical review. Czech J Soc Sci Bus Econ. 2014;3(2).

26. Bunthuwun Laohasirichaikul Howard Combs SC. Effective customer relationship management of health care: a study of hospitals in Thailand. J Manag Mark Res. 2011;6:1-12. 